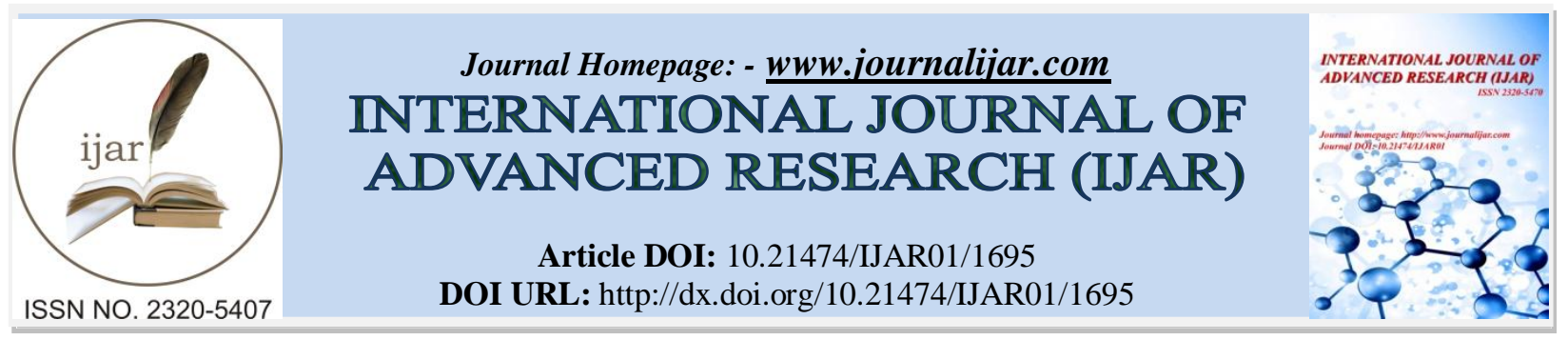

RESEARCH ARTICLE

\title{
CHEMICO-ANALYSIS OF SEMIOCHEMICAL COMPOUNDS FROM PRE-EXISTING COLONY COMPONENTS INFLUENCING OVIPOSITION IN PHLEBOTOMUS ARGENTIPES (DIPTERA: PSYCHODIDAE)
}

Aarti Rama', Pradeep Das ${ }^{2}$ and "Vijay Kumar'

1. Department of Vector Biology and Control, Rajendra Memorial Research Institute of Medical Sciences (Indian Council of Medical Research), Agamkuan, Patna - 800 007, Bihar, India.

2. Deaprtment of Molecular Biology, Rajendra Memorial Research Institute of Medical Sciences (Indian Council of Medical Research), Agamkuan, Patna - 800 007, Bihar, India.

\section{Manuscript Info}

[.........................

Manuscript History

Received: 12 July 2016

Final Accepted: 13 August 2016

Published: September 2016

Key words:-

Phlebotomus argentipes,

Visceral leishmaniasis (VL),

Oviposition,

Semiochemicals,

Gas Chromatography-Mass

Spectrometry (GC-MS),

Heptacosane [C27H56],

Cuticular Hydrocarbon (CHC).

\section{Abstract}

Objective: Increasing instances of insecticide resistance among Phlebotomus argentipes- a prominent vector of Visceral leishmaniasis (VL) in Indian subcontinent has opportunized vector control strategy to negotiate with the potentiality of semiochemical for controlling the menace caused by them. Behavioural bioassay experiments with the fractionated extracts of frass and conspecific eggs, being obtained as remnant ingredients from the pre-existing colony of $P$. argentipes, revealed its potentiality for attracting and stimulating female sand flies towards itself purposely for oviposition, leading to the regulation of its generation.

Method: Following the observation in the previous study, present study documents the characterization of responsible semiochemical compound(s) of aqueous extract of frass and Hexane extract of conspecific eggs via Gas Chromatography coupled with Mass Spectrometry (GC-MS) technique.

Novel and exclusive result: Heptacosane $\left[\mathrm{C}_{27} \mathrm{H}_{56}\right]$, a Cuticular Hydrocarbon (CHC) was characterized as a common semiochemical compound in both type of extracts responsible for attracting and stimulating oviposition responses among $P$. argentipes.

Conclusion: The identified chemical compound eliciting oviposition responses among the $P$. argentipes would further complement the novel targeted surveillance approach of sand fly population by baiting them with an attractive lure for orienting them towards the desired site treated with attract-and-kill oviposition traps ultimately reducing human resource devastation at a mass scale. Also, it holds futuristic attribute towards improved maintenance and productivity of laboratory-bred sand fly colonies that usually threatened due to high mortality of ovipositing females.

Copy Right, IJAR, 2016,. All rights reserved.

Corresponding Author:- Dr. Vijay Kumar. 


\section{Introduction:-}

Visceral leishmaniasis (VL), rooted in 88 endemic countries (i.e., 22 in the New World and 66 in the Old World) putting 350 million people at risk with global occurrence of 500,000 cases and 50,000 deaths per year, ranks secondlargest parasitic killer in the world (after malaria) (WHO, 2002). Of the 500,000 new cases of VL, more than 90\% are reported from the developing nations viz., India, Nepal, Bangladesh, southern Sudan and north-east Brazil and hence gripped the title of 'health concern' since last few decades.

In north-eastern endemic states of India and its neighboring nations, Phlebotomus argentipes (Diptera: Psychodidae) Annandale and Brunetti serve as a prominent VL vector and for conquering the disease, vector control strategy through DDT @ 1gm/ $/ \mathrm{m}^{2}$ remained mainstay since 1976 (Mukhopadhyay et al., 1987). The widespread use of this insecticide however lead to the development of insecticide resistance among P. argentipes (Rama et al., 2015; Kumar et al., 2015), making the use of DDT so ineffective leading to its resurgence even after 30 days of spray (Chowdhary et al., 2011). Consequently, increasing instances of insecticide resistance have opportunized vector control strategy to negotiate with the potentiality of semiochemical for controlling this VL vector specie.

Knowing fact about the semiochemicals, being signaling chemical substances, elicits behavioral and physiological responses in other organism as well help them to switch on the defending/attacking action against its predators/host specie. By influencing the colonization of a subsequent host and natural enemy population dynamics, semiochemicals can thereby be used to disrupt or direct them away from the host and attract them towards the areas where they can be controlled (e.g. the "push-pull" strategy). In this response, semiochemicals act by manipulating insect behaviour rather than by toxicity and thus offer environmentally benign means of vector management with which to minimize, supplement, or in the long-term replaces the use of broad-spectrum insecticides under Integrated Vector Management (IVM).

In continuation with our previously reported bioassay performance in female $P$. argentipes for the assessment of semiochemical based oviposition response towards the chief ingredients of pre-existing colony (Rama et al., 2014), an approach work has been performed purposely for characterization of responsible chemical compound eliciting oviposition responses among this vector specie. For this purpose, effective extracts i.e., aqueous extract of frass and hexane extract of conspecific eggs were probed under the Gas Chromatography coupled with Mass Spectrometry (GC-MS) technique (Koek et al., 2011; Srinivasan and Kumaravel, 2015) following to which Heptacosane [ $\mathrm{C}_{27} \mathrm{H}_{56}$ a Cuticular Hydrocarbon (CHC) was characterized as a common semiochemical compound in the both types of extracts responsible for attracting and stimulating ovipositing female $P$. argentipes.

The significance of CHC was established in the P. argentipes by the various researchers (Gebre-Michael et al., 2009; Ryan et al., 1986; Kamhawi et al., 1992) but none of them either characterized or elaborated its type. Therefore, present study was conducted for characterization of semiochemical compound from pre-existing colony component. The identified chemical compound i.e., Heptacosane $\left[\mathrm{C}_{27} \mathrm{H}_{56}\right]$ bearing semiochemical property, eliciting oviposition attractancy and stimulancy among $P$. argentipes would further complement the development of an attractive blend for attracting pathogenic gravid vectors at a particular site lured with selective natural insecticide chemical/biological control agents, reducing human resource devastation at mass scale.

\section{Material and Methods:-}

For characterization of responsible semiochemical compound(s) of remnant ingredients obtained from the preexisting colony of $P$. argentipes via Gas Chromatography coupled with Mass Spectrometry (GC-MS) technique, frass (organically enriched larval food remains containing particulate of hatched eggs, exuviae dead remains of larvae, etc) and conspecific eggs served as the foremost pre-requisites. The semiochemical particulate of frass and conspecific eggs were properly prepared after dissolving in aqueous (polar) and hexane (nonpolar) medium respectively for the effective release of aroma attracting ovipositing sand flies \& compelling them to oviposit on the treated surface (Rama et al., 2014). For the chemical analysis, protocol of extract preparation as described in (Rama et al., 2014) was strictly followed purposely for assessing attactancy and stimulancy responses of $P$. argentipes with the help of bioassay experiments that were performed at the controlled environment of insectarium at Vector Biology and Control Department of RMRIMS (ICMR), Patna, Bihar-07 (India).

For the chemical analysis of extracts, $2 \mu \mathrm{l}$ of each prepared extract samples were injected into the injecting section of GC programme Scion 436-GC Bruker model coupled with a Triple, quadruple mass spectrometer with fused silica capillary column BR-5MS (5\% Diphenyl /95\% Dimethyl polysiloxane) and Length: 30 m; Internal diameter: 
$0.25 \mathrm{~mm}$; Thickness: $0.25 \mu \mathrm{m}$. Helium gas (99.999\%) was used as the carrier gas at a constant flow rate of $1 \mathrm{ml} / \mathrm{min}$ and an injection volume of $2 \mu \mathrm{l}$ was employed (split ratio of 10:1) (Srinivasan and Kumaravel, 2015). The column oven temperature program was as follows: $110{ }^{\circ} \mathrm{C}$ hold for $3.50 \mathrm{~min}$, Up to $200{ }^{\circ} \mathrm{C}$ at the rate of $10{ }^{\circ} \mathrm{C} / \mathrm{min}$-No hold, Up to $280{ }^{\circ} \mathrm{C}$ at the rate of $5{ }^{\circ} \mathrm{C} / \mathrm{min}-9$ min hold. The injector temperature was at $280{ }^{\circ} \mathrm{C}$ and total $\mathrm{GC}$ running time was $37.50 \mathrm{~min}$. This last increase was to clean the column from any residues. The mass spectrometer was operated in the positive electron ionization (EI) mode with ionization energy of 70eV. The solvent delay was 0-3.5 min. A scan interval of 0.5 seconds and fragments from $\mathrm{m} / \mathrm{z} 50-500 \mathrm{amu}$ was programmed. The inlet line temperature was set at $290{ }^{\circ} \mathrm{C}$, source temperature $250{ }^{\circ} \mathrm{C}$. The relative percentage amount of each component was calculated by comparing its average peak area to the total areas. Software adopted to handle mass spectra and chromatograms was MS Work station 8. The NIST Version 2.0 library database of National Institute Standard and Technology (NIST) having more than 62,000 patterns was used for identifying the chemical components. The spectrum of the unknown component was compared with the spectrum of the known components stored in the NIST library. The name, molecular weight and structure of the components of the observed materials were confirmed. The GC-MS/MS was performed at Food Safety and Quality Testing Laboratory, Indian Institute of Crop Processing Technology (Ministry of Food Processing Industries, Government of India), Pudukkotai Road, Thanjavur.

\section{Results and Discussion:-}

Overall 12 and 18 compounds were identified through the GC-MS/MS analysis of Aqueous Extract of Frass (AEF) and Hexane Extract of Conspecific Eggs (HEE) obtained from the pre-existing colony of $P$. argentipes and is enlisted in following Table 1 and Table 2 respectively.

Table 1:- Compounds identified in Aqueous extract of Frass (AEF)

\begin{tabular}{|c|c|c|c|c|c|}
\hline S.No & Name of Compound & $\begin{array}{l}\text { Molecular } \\
\text { Formulae }\end{array}$ & $\begin{array}{l}\text { Molecular } \\
\text { Weight }\end{array}$ & $\begin{array}{l}\text { Peak } \\
\text { Area \% }\end{array}$ & RT \\
\hline 1 & Phenol, 2-methoxy-3-(2-propenyl)- & $\mathrm{C}_{10} \mathrm{H}_{12} \mathrm{O}_{2}$ & 164 & 7.39 & 4.64 \\
\hline 2 & Benzenepropanoic acid 1-methylethyl ester & $\mathrm{C}_{12} \mathrm{H}_{16} \mathrm{O}_{2}$ & 192 & 2.40 & 7.64 \\
\hline 3 & Phenol, 2-methoxy-4-(2-propenyl)-, acetate & $\mathrm{C}_{12} \mathrm{H}_{14} \mathrm{O}_{3}$ & 206 & 2.50 & 7.90 \\
\hline 4 & Diethyl Phthalate & $\mathrm{C}_{12} \mathrm{H}_{14} \mathrm{O}_{4}$ & 222 & 2.50 & 11.05 \\
\hline 5 & 5,8,11-Heptadecatrien-1-ol & $\mathrm{C}_{17} \mathrm{H}_{30} \mathrm{O}$ & 250 & 1.11 & 11.22 \\
\hline 6 & Pentadecanoic acid & $\mathrm{C}_{15} \mathrm{H}_{30} \mathrm{O}_{2}$ & 242 & 0.55 & 13.14 \\
\hline 7 & Phthalic acid, isobutyl octyl ester & $\mathrm{C}_{20} \mathrm{H}_{30} \mathrm{O}_{4}$ & 334 & 5.08 & 14.30 \\
\hline 8 & 1,2-Benzenedicarboxylic acid, butyl octyl ester & $\mathrm{C}_{20} \mathrm{H}_{30} \mathrm{O}_{4}$ & 334 & 3.33 & 15.54 \\
\hline 9 & 9,12-Octadecadienoic acid (Z,Z)- & $\mathrm{C}_{18} \mathrm{H}_{32} \mathrm{O}_{2}$ & 280 & 2.50 & 18.07 \\
\hline 10 & $\begin{array}{l}\text { 9,12,15-Octadecatrienoic } \quad \text { acid, } \\
\text { bis[(trimethylsilyl)oxy]propyl ester, (Z,Z,Z)- }\end{array}$ & $\mathrm{C}_{27} \mathrm{H}_{52} \mathrm{O}_{4} \mathrm{Si}_{2}$ & 496 & 0.46 & 23.83 \\
\hline 11 & Heptacosane & $\mathbf{C}_{27} \mathbf{H}_{56}$ & 380 & 44.09 & 27.16 \\
\hline 12 & 1-Monolinoleoylglycerol trimethylsilyl ether & $\mathrm{C}_{27} \mathrm{H}_{54} \mathrm{O}_{4} \mathrm{Si}_{2}$ & 498 & 28.10 & 31.75 \\
\hline
\end{tabular}

Table 2:- Compounds identified in Hexane extract of Conspecific Eggs (HEE)

\begin{tabular}{|c|c|c|c|c|c|}
\hline S.No & Name of Compound & $\begin{array}{l}\text { Molecular } \\
\text { Formulae }\end{array}$ & $\begin{array}{l}\text { Molecular } \\
\text { Weight }\end{array}$ & $\begin{array}{l}\text { Peak } \\
\text { Area \% }\end{array}$ & RT \\
\hline 1 & 2,2,7,7-Tetramethyltricyclo[6.2.1.0(1,6)]undec-4-en-3-one & $\mathrm{C}_{15} \mathrm{H}_{22} \mathrm{O}$ & 218 & 0.15 & 9.58 \\
\hline 2 & $\begin{array}{l}\text { 1,3-Cyclohexadiene, } \\
\text { methyl-, }\left[\mathrm{S}-\left(\mathrm{R}^{*}, \mathrm{~S}^{*}\right)\right]-\end{array}$ & $\mathrm{C}_{15} \mathrm{H}_{24}$ & 204 & 0.06 & 9.88 \\
\hline 3 & Butylated Hydroxytoluene & $\mathrm{C}_{15} \mathrm{H}_{24} \mathrm{O}$ & 220 & 0.10 & 9.98 \\
\hline 4 & Phthalic acid, isobutyl octyl ester & $\mathrm{C}_{20} \mathrm{H}_{30} \mathrm{O}_{4}$ & 334 & $\mathbf{0 . 5 0}$ & $\mathbf{1 4 . 3 0}$ \\
\hline 5 & 7,9-Di-tert-butyl-1-oxaspiro(4,5)deca-6,9-diene-2,8-dione & $\mathrm{C}_{17} \mathrm{H}_{24} \mathrm{O}_{3}$ & 276 & 0.01 & 14.93 \\
\hline 6 & Methoxyacetic acid, 2-tetradecyl ester & $\mathrm{C}_{17} \mathrm{H}_{34} \mathrm{O}_{3}$ & 286 & 0.08 & 16.12 \\
\hline 7 & Sulfurous acid, hexyl pentadecyl ester & $\mathrm{C}_{21} \mathrm{H}_{44} \mathrm{O}_{3} \mathrm{~S}$ & 376 & 0.38 & 17.52 \\
\hline 8 & Octadecane, 2-methyl- & $\mathrm{C}_{19} \mathrm{H}_{40}$ & 268 & 1.49 & 18.98 \\
\hline 9 & Eicosane, 2-methyl- & $\mathrm{C}_{21} \mathrm{H}_{44}$ & 296 & 3.23 & 20.46 \\
\hline 10 & Heneicosane & $\mathrm{C}_{21} \mathrm{H}_{44}$ & 296 & 4.77 & 21.94 \\
\hline 11 & Sulfurous acid, octadecyl pentyl ester & $\mathrm{C}_{23} \mathrm{H}_{48} \mathrm{O}_{3} \mathrm{~S}$ & 404 & 5.21 & 23.41 \\
\hline 12 & 2-methylhexacosane & $\mathrm{C}_{27} \mathrm{H}_{56}$ & 380 & 6.46 & 24.85 \\
\hline
\end{tabular}




\begin{tabular}{|l|l|l|l|l|l|}
\hline 13 & 2-methyloctacosane & $\mathrm{C}_{29} \mathrm{H}_{60}$ & 408 & 10.03 & 26.27 \\
\hline $\mathbf{1 4}$ & Heptacosane & $\mathbf{C}_{\mathbf{2 7}} \mathbf{H}_{\mathbf{5 6}}$ & $\mathbf{3 8 0}$ & $\mathbf{2 0 . 7 9}$ & $\mathbf{2 7 . 6 6}$ \\
\hline 15 & Docosane, 7-hexyl- & $\mathrm{C}_{28} \mathrm{H}_{58}$ & 394 & 18.55 & 29.03 \\
\hline 16 & Tetracosane, 11-decyl- & $\mathrm{C}_{34} \mathrm{H}_{70}$ & 478 & 14.36 & 30.58 \\
\hline 17 & Hentriacontane & $\mathrm{C}_{31} \mathrm{H}_{64}$ & 436 & 9.33 & 32.49 \\
\hline 18 & Docosane, 11-decyl- & $\mathrm{C}_{32} \mathrm{H}_{66}$ & 450 & 4.50 & 34.71 \\
\hline
\end{tabular}

Of these identified compounds only 2 chemical compounds i.e., Phthalic acid, isobutyl octyl ester $\left[\mathrm{C}_{20} \mathrm{H}_{30} \mathrm{O}_{4}\right.$, M.W334] and Heptacosane $\left[\mathrm{C}_{27} \mathrm{H}_{56}, \mathrm{M} . \mathrm{W}-380\right]$ were identified to be co-existed in both type of extracts (Figure 1 and Figure 2) and are expected to elicit oviposition responses (either in aggregate or separate form) in female $P$. aregentipes.

\section{Fìgure 1 (AEF)}

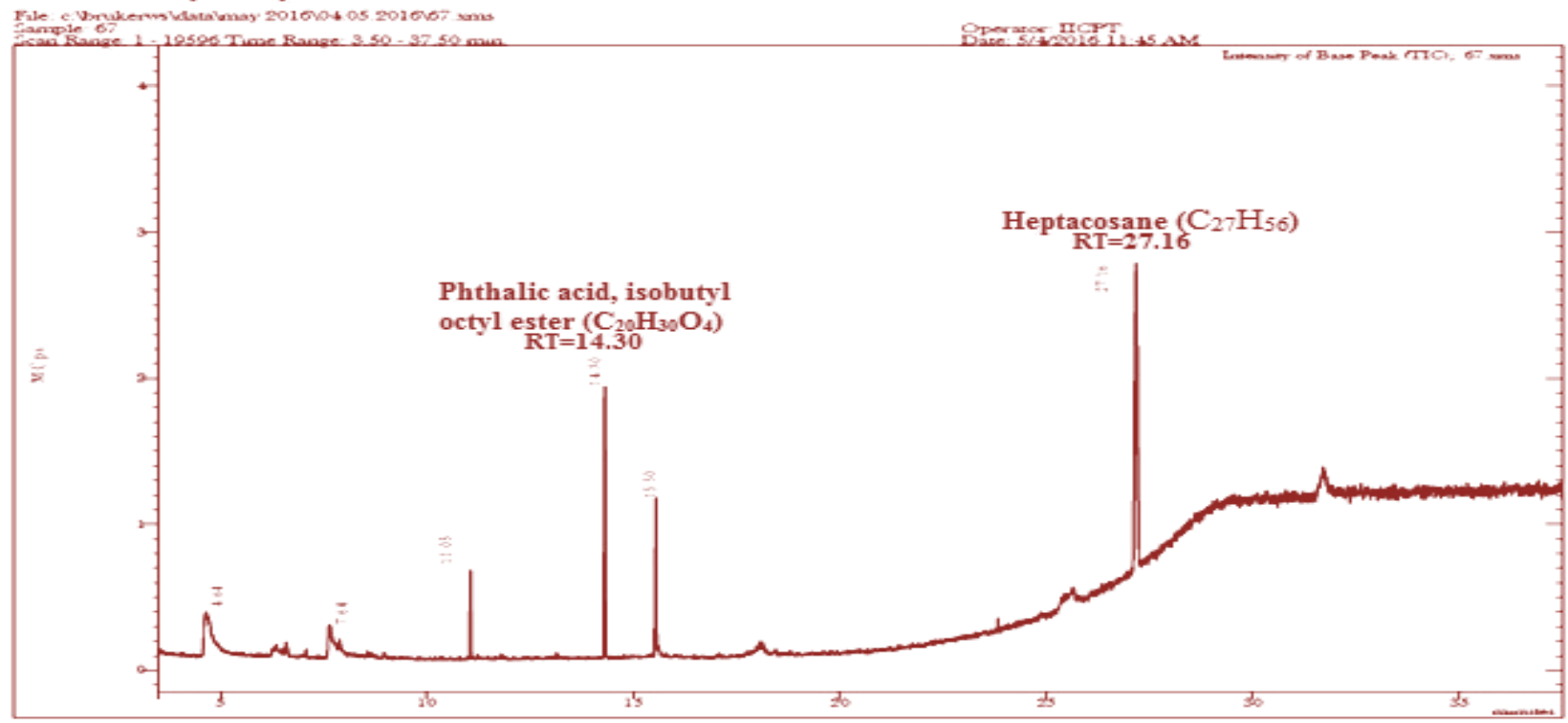

Figure 1:- GC-MS Chromatogram of Aqueous extract of Frass (AEF)

Figure 2 (HEE)

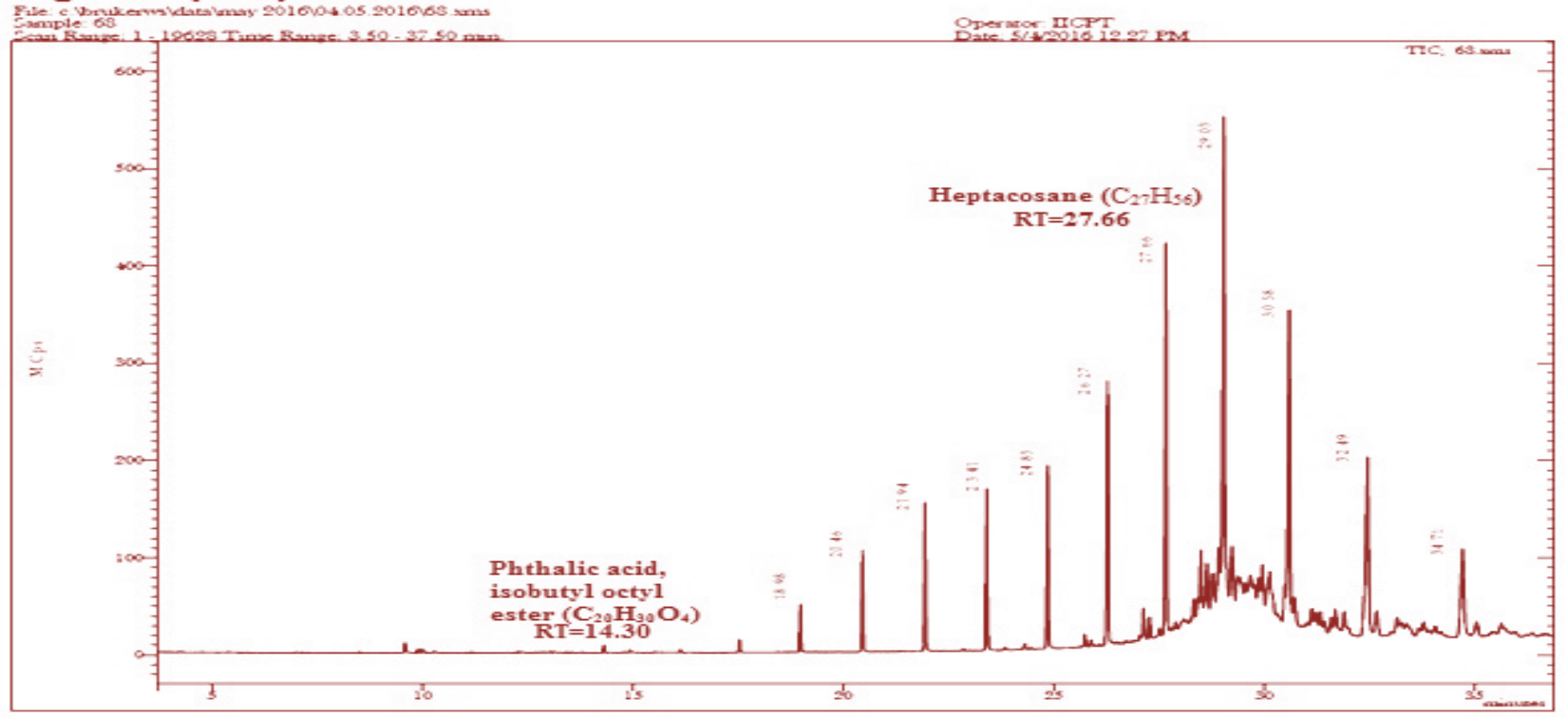

Figure 2:- GC-MS Chromatogram of Hexane Extract of Conspecific Eggs (HEE) 
Following the published information regarding the significance of chemical compounds eliciting behavioural responses in insects, it was observed that Phthalic acid, isobutyl octyl ester $\left[\mathrm{C}_{20} \mathrm{H}_{30} \mathrm{O}_{4}\right]$ (Figure 3.a) being aromatic di-carboxylic acid compound bears antibacterial and antioxidant properties suggesting its potency in eliciting insecticidal activities along with many proteinous and non-proteinous toxins (Ullah et al., 2014) and hence doesn't scope for an oviposition attractant/ stimulant in this vector species.

Contrary to this, Heptacosane $\left[\mathrm{C}_{27} \mathrm{H}_{56}\right]$ (a straight-chain alkane, with 27-carbon atoms) (Figure 3.b) representing $\mathrm{CHC}$, occuring in the cuticular lipids of insects, serve as a sex attractant, species and caste recognition cues, alarm pheromones and defense mechanisms (Howard et al., 1982). It is characterized as a common semiochemical compound in both type of extracts and hence expected for attracting and stimulating responses among ovipositing $P$. argentipes.

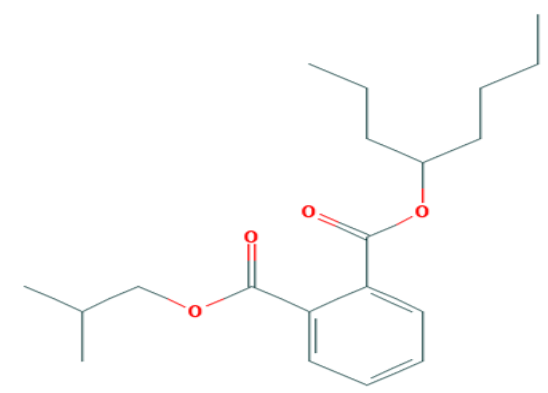

(a) Phthalic acid, isobutyl octyl ester $\left[\mathrm{C}_{20} \mathrm{H}_{30} \mathrm{O}_{4}\right]$ (b) Heptacosane $\left[\mathrm{C}_{27} \mathrm{H}_{56}\right]$

Figure 3:- Structure of Semio-chemical Compounds co-existed in Aqueous extract of Frass (AEF) and Hexane Extract of Conspecific Eggs (HEE), identified via GC-MS (Source: database of National Institute Standard and Technology (NIST)

\section{Properties and Significance of CHCs in Phlebotomus argentipes}

CHCs are the inherent property of insect, forms the protective desiccation barriers and hence serve as a component for complex species differentiation (Gebre Michael et al., 2009). There are several distinct molecule types in each specimen (chain length from C-23-C-37, with differing position of double bonds or methyl branches). The presence of long-chained hydrocarbons coating at the insects' exoskeleton suggests chemical signature that contains dual information about colony membership and fertility status of membership. Colonies have a distinct odor that underlies in-mates recognition i.e., hydrocarbon profile is perceived and assessed during encounters between individual insects; to discriminates friends and foes based upon the discrepancy of CHC (Gebre Michael et al., 2009). However, the discrimination in constituent of CHCs also depends upon various factors viz., environment factor (habitat, temperature, relative humidity, season etc.) (Ryan et al., 1986), genetical configuration in sand flies (Kamhawi et al., 1992) that could serve as an informative topic of research if explored.

\section{Conclusion:-}

Female $P$. argentipes being haematophagy entails blood meal from the human host and transmit devastating parasite L. donovani causing Visceral leishmaniasis (VL) or Kala-azar among them and hence gains significant importance in health prospect. For preventing and controlling the VL and other vector borne diseases, among existing strategies i.e., early detection and treatment of cases, vector control strategy remained mainstay for inhibiting the spread of disease. Due to the limited effectiveness and high public public health risk offered by the conventional vector control methods demands the development of new ecologically-based methods to control sand fly populations (Hotez et al., 2012). Attracting the vector to a trap containing attractant mixed with lethal chemicals has been well described as a control method for vector mosquitoes and other agricultural pests, for which the term 'attract and kill' has been introduced as an innovative and effective commercially available control method (Zeichner and Debboun, 2011). In terms of vector control approach, an oviposition-attractant based approach targets older females that have already acquired their first blood meal and are ready to lay their eggs and move on to their second blood meal, that serve as a critical stage in disease transmission. Therefore, oviposition attractants are especially effective in interrupting the disease transmission cycle in contrast to other types of semiochemicals which mainly attract the young, nulliparous, non-blood fed females as established in new-world sand flies (Dougherthy and Hamilton, 1997) but still neglected in old world sand flies (Kumar et al., 2013). In this respect, present study is an exclusive lead 
work of previously dealt semiochemical compounds i.e., Frass and Conspecific eggs being obtained as remnant ingredients from the pre-existing colony of $P$. argentipes (Kumar et al., 2013; Rama et al., 2014). The identified chemical compound i.e., Heptacosane $\left[\mathrm{C}_{27} \mathrm{H}_{56}\right]$ - a Cuticular Hydrocarbon (CHC) bearing semiochemical properties are potential in attracting and stimulating oviposition responses in $P$. argentipes. This compound will further be optimized to serve as an attractive lure for the potential commercial production of desired attract-and-kill oviposition traps. These oviposition traps can provide the basis for novel targeted surveillance approach of sand fly population. This control method has exhibited promising results on mosquito species and has been suggested as a potential sand fly control method (Muller et al., 2010; Wasserberg et al., 2014). Furthermore, heptacosane possess futuristic attribute towards improved maintenance and productivity of laboratory-bred sand fly colonies that usually threatened due to high mortality of ovipositing females.

\section{Acknowledgements:-}

Present work is a part of study under PhD programme [Registration No. 3700/PhD. (Sc.) proceed 2014] progressing under the supervision of University of Calcutta, Kolkata, India; financially sponsored by University Grant Commission, India with vide grant number [RGNF 2012-13-ST-BIH-20305] and RMRIMS (ICMR), Agamkuan, Patna-07, Bihar, India with study ID No. [INT - 83 -VBC] entitling 'Study on the semiochemical mediated response in the oviposition behaviour of $P$. argentipes' approved by the Scientific Advisory Committee (SAC) of Rajendra Memorial Research Institute of Medical Sciences (ICMR) in year 2012.

The authors cordially express their gratitude towards NK Sinha, SA Khan, AK Mandal, BB Prasad and all members of Vector Biology and Control Department for their excellent technical support and help during the experiment and manuscript documentation session. Thanks are also due to the Scientific Advisory Committee (SAC) of Rajendra Memorial Research Institute of Medical Sciences (ICMR), Institutional Ethical Committee as well as to the Animal Ethics Committee for their kind approval to conduct the research study. Last but not least Dr. S Kumaravel of Food Safety and Quality Testing Laboratory, Indian Institute of Crop Processing Technology (Ministry of Food Processing Industries, Government of India), Pudukkotai Road, Thanjavur and Dr. (Mrs.) Nisha Mathew (ScientistE) of Vector Control Research Centre, Pondicherry are highly acknowledged for their fantastic contribution for conducting the research successfully.

\section{Conflict Of Interest:-}

There is no conflict of interest among the authors

\section{References:-}

1. Chowdhury, R., Huda, M.M., Kumar, V., Das, P., Joshi, A.B., Banjara, M.R., Akhtar, S., Kroeger, A., Krishnakumari, B., Petzold, M., Mondal, D., Das, M.L. (2011): The Indian and Nepalese programmes of indoor residual spraying for the elimination of visceral leishmaniasis: performance and effectiveness. Annals of Tropical Medicine and Parasitology, 105 (1):31-45.

2. Dougherty, M., Hamilton, G. (1997): Dodecanoic Acid Is the Oviposition Pheromone ofLutzomyia longipalpis. Journal of Chemical Ecology, 23(12), 2657-2671.

3. Gebre-Michael, T., Lane, R.P., Phillips, A., Milligan, P. Molyneux, D.H. (2009): 'Contrast in the cuticular hydrocarbons of sympatric Phlebotomus (Synphlebotomus) females (Diptera: Phlebotominae)', Bulletin of Entomological Research. 84(2), 225-231. doi: 10.1017/S0007485300039730

4. Hotez, P.J., Savioli, L., Fenwick, A. (2012): Neglected tropical diseases of the Middle East and North Africa: review of their prevalence, distribution, and opportunities for control. PLoS Negl Trop Dis, 6(2), e1475.

5. Howard, R.W., Blomquist, G.J. (1982): Chemical ecology and biochemistry of insect hydrocarbons. Annual review of entomology, 27(1), 149-172.

6. Kamhawi, S., Lane, R.P., Cameron, M., Phillips, A., Milligan, P., Molyneux, D.H. (1992): The cuticular hydrocarbons of Phlebotomus argentipes (Diptera: Phlebotominae) from field populations in northern India and Sri Lanka, and their change with laboratory colonization. Bulletin of Entomological Research, 82(02), 209-212.

7. Koek, M.M., Jellema, R.H., van der Greef, J., Tas, A.C., Hankemeier, T. (2011): Quantitative metabolomics based on gas chromatography mass spectrometry: status and perspectives. Metabolomics, 7(3), 307-328. http://doi.org/10.1007/s11306-010-0254-3

8. Kumar, V., Rama, A., Kesari, S., Bhunia, G.S., Dinesh, D.S., Das, P. (2013): Oviposition behaviour of Phlebotomus argentipes - A laboratory-based study. Memórias do Instituto Oswaldo Cruz, 108(8), 1065-1067. Epub October 02, 2013.https://dx.doi.org/10.1590/0074-0276130003 
9. Kumar, V., Shankar, L., Kesari, S., Bhunia, G.S., Dinesh, D.S., Mandal, R., Das, P. (2015): Insecticide susceptibility of Phlebotomus argentipes \& assessment of vector control in two districts of West Bengal, India. The Indian Journal of Medical Research, 142(2), 211-215. http://doi.org/10.4103/0971-5916.164260

10. Mukhopadhyay, A.K., Chakravarty, A.K., Kureel, V.R., Shivraj. (1987): Resurgence of Phlebotomus argentipes \& Ph. papatasi in parts of Bihar (India) after DDT spraying. Indian J Med Res, 85:158-160.

11. Müller, G.C., Junnila, A., Schlein, Y. (2010): Effective control of adult Culex pipiens by spraying an attractive toxic sugar bait solution in the vegetation near larval habitats. Journal of medical entomology, 47(1), 63-66.

12. Rama, A., Kumar, V., Kesari, S., Dinesh, D.S., Das, P (2014): Exploring semiochemical based oviposition response of Phlebotomus argentipes (Diptera: psychodidae) towards pre-existing colony ingredients. International Journal of Medicine and Pharmaceutical Sciences, 4(4), 35-46.

13. Rama, A., Kumar, V., Kesari, S., Singh, V.P., Das, P. (2015): Monitoring Susceptibility Status of Phlebotomus argentipes (Diptera: Psychodidae) at Bihar (India) for the Procurement of Homozygous DDT Resistant Colony. J Trop Dis, 3:170. doi:10.4172/2329891X.1000170

14. Ryan, L.A., Phillips, A., Milligan, P., Lainson, R., Molyneux, D.H., Shaw, J.J. (1986): Separation of female Psychodopygus wellcomei and P. complexus (Diptera: Psychodidae) by cuticular hydrocarbon analysis. Acta tropica, 43(1), 85-89.

15. Srinivasan, K., Kumaravel, S. (2015): Unraveling the Potential Phytochemical Compounds of Gymnema Sylvestre through GC-MS Study. International Journal of Pharmacy and Pharmaceutical Sciences, 8(1), 450453.

16. Ullah, I., Khan, A.L., Ali, L., Khan, A.R., Waqas, M., Lee, I.J., Shin, J.H. (2014): An insecticidal compound produced by an insect-pathogenic bacterium suppresses host defenses through phenoloxidase inhibition. Molecules, 19(12), 20913-20928. doi:10.3390/molecules191220913

17. Wasserberg, G., Kirsch, P., D Rowton, E. (2014): Orientation of colonized sand flies Phlebotomus papatasi, P. duboscqi, and Lutzomyia longipalpis (Diptera: Psychodidae) to diverse honeys using a 3-chamber in-line olfactometer. Journal of Vector Ecology, 39(1), 94-102.

18. World Health Organisation. (2002): The World Health Report, Geneva, Switzerland. http://www.who.int/whr/2002/en/whr02_en.pdf.

19. Zeichner, B. C., Debboun, M. (2011): The lethal ovitrap: a response to the resurgence of dengue and chikungunya. US Army Med Dep J, 4-11. 